Daniel Tuchscherer

Werner J. Z'Graggen

Christina Passath

Jukka Takala

Christer Sinderby

Lukas Brander

\section{Neurally adjusted ventilatory assist in patients with critical illness-associated polyneuromyopathy}

Received: 8 February 2011

Accepted: 3 August 2011

Published online: 3 November 2011

C Copyright jointly held by Springer and ESICM 2011

Clinical Trial.gov Identifiers:

NCT00614562 and NCT00941044.

Selected results were presented in abstract format at the 29th International Symposium on Intensive Care and Emergency Medicine, Brussels, March 24-27, 2009.

\section{Electronic supplementary material}

The online version of this article

(doi:10.1007/s00134-011-2376-0) contains supplementary material, which is available to authorized users.

D. Tuchscherer - C. Passath .

J. Takala $\cdot$ L. Brander

Department of Intensive Care Medicine, Inselspital, Bern University Hospital and University of Bern, Bern, Switzerland

\section{W. J. Z'Graggen}

Department of Neurosurgery, Inselspital, Bern University Hospital and University of Bern, Bern, Switzerland

\section{W. J. Z'Graggen}

Department of Neurology, Inselspital, Bern University Hospital and University of Bern, Bern, Switzerland

\section{Sinderby}

Interdepartmental Division of Critical Care Medicine, Department of Critical Care Medicine, St. Michael's Hospital, University of Toronto, Toronto, Canada
C. Sinderby

Keenan Research Center, Li Ka Shing Knowledge Institute of St. Michael's Hospital, Toronto, Canada

\section{Brander ( $)$}

Department of Anesthesia and Intensive Care Medicine, Luzerner Kantonsspital, 16, 6000 Lucerne, Switzerland e-mail: lukas.brander@bluewin.ch

\section{Abstract Purpose: Diaphrag-} matic electrical activity $\left(\mathrm{EA}_{\mathrm{di}}\right)$, reflecting respiratory drive, and its feedback control might be impaired in critical illness-associated polyneuromyopathy (CIPM). We aimed to evaluate whether titration and prolonged application of neurally adjusted ventilatory assist (NAVA), which delivers pressure $\left(P_{\mathrm{aw}}\right)$ in proportion to $\mathrm{EA}_{\mathrm{di}}$, is feasible in CIPM patients. Methods: Peripheral and phrenic nerve electrophysiology studies were performed in 15 patients with clinically suspected CIPM and in 14 healthy volunteers. In patients, an adequate NAVA level (NAVAal) was titrated daily and was implemented for a maximum of $72 \mathrm{~h}$. Changes in tidal volume $\left(V_{\mathrm{t}}\right)$ generation per unit of $\mathrm{EA}_{\mathrm{di}}\left(V_{\mathrm{t}} / \mathrm{EA}_{\mathrm{di}}\right)$ were assessed daily during standardized tests of neuroventilatory efficiency (NVET).

Results: In patients (median [range], 66 [44-80] years), peripheral electrophysiology studies confirmed
CIPM. Phrenic nerve latency (PNL) was prolonged and diaphragm compound muscle action potential (CMAP) was reduced compared with healthy volunteers $(p<0.05$ for both). NAVAal could be titrated in all but two patients. During implementation of NAVAal for 61 (37-64) h, the $\mathrm{EA}_{\mathrm{di}}$ amplitude was 9.0 (4.4-15.2) $\mu \mathrm{V}$, and the $V_{\mathrm{t}}$ was 6.5 (3.7-14.3) $\mathrm{ml} / \mathrm{kg}$ predicted body weight. $V_{\mathrm{t}}$, respiratory rate, $\mathrm{EA}_{\mathrm{di}}$, $\mathrm{PaCO}_{2}$, and hemodynamic parameters remained unchanged, while $\mathrm{PaO}_{2} /$ $\mathrm{FiO}_{2}$ increased from 238 (121-337) to $282(150-440) \mathrm{mmHg}(p=0.007)$ during NAVAal. $V_{\mathrm{t}} / \mathrm{EA}_{\mathrm{di}}$ changed by $-10(-46 ;+31) \%$ during the first NVET and by $-0.1(-26 ;+77) \%$ during the last NVET $(p=0.048)$. Conclusion: In most patients with CIPM, $\mathrm{EA}_{\mathrm{di}}$ and its feedback control are sufficiently preserved to titrate and implement NAVA for up to 3 days. Whether monitoring neuroventilatory efficiency helps inform the weaning process warrants further evaluation.

Keywords Positive pressure respiration - Breathing pattern . Diaphragm - Electromyography . Respiratory therapy · Polyneuropathy 


\section{Introduction}

Critical illness-associated polyneuromyopathy (CIPM) is common in long-stay intensive care patients and contributes to ventilator dependency and prolonged rehabilitation [1-5]. Major alterations of the phrenic nerve, including axonal degeneration [6], increased phrenic nerve latency (PNL), and decreased diaphragm compound muscle action potential (CMAP), have been described in CIPM, indicating dysfunction of the phrenic nerve-diaphragm unit [7-10].

Neurally adjusted ventilatory assist (NAVA) delivers pressure to the airways $\left(P_{\text {aw }}\right)$ in synchrony and linear proportionality to the electrical activity of the diaphragm $\left(\mathrm{EA}_{\mathrm{di}}\right)$ [11], which is a validated measure of global respiratory drive [12-15]. A number of features unique to NAVA may be beneficial in patients with CIPM. For example, using $\mathrm{EA}_{\mathrm{di}}$ to control the ventilator not only guarantees synchrony with the patient's respiratory demand in each neural breath independent of muscular strength and assist level [16-20], but also allows individual determination of an adequate level of respiratory muscle unloading based on neural feedback control of EA $_{\mathrm{di}}$ without overly suppressing respiratory drive [16, 21-27]. Using an assist level titrated to the individual's needs could be helpful in preventing both disuse atrophy and fatigue of respiratory muscles. Furthermore, monitoring neuro-ventilatory efficiency, i.e., tidal volume $\left(V_{\mathrm{t}}\right)$ per unit of $\mathrm{EA}_{\mathrm{di}}$, provides information on how the patient's ability to translate neural drive into $V_{\mathrm{t}}$ generation progresses over time [24].

NAVA depends on the integrity of complex feedback systems that control $\mathrm{EA}_{\mathrm{di}}[12-15]$. It is not known to what extent the function of the phrenic nerve-diaphragm unit is affected in spontaneously breathing CIPM patients and whether the $\mathrm{EA}_{\mathrm{di}}$ in these patients can be used to control a ventilator.

We aimed to assess the degree of neuromuscular impairment in a group of CIPM patients compared to healthy volunteers and to examine whether titration and application of NAVA for up to 3 days are feasible in these patients.

\section{Methods}

Patients and study design

The protocol was approved by the Ethics Committee of the Canton of Bern, Switzerland. Patients were recruited from February 2008 to October 2008. Written informed consent was obtained from the next of kin and from an independent physician. For detailed methods and exclusion criteria see the electronic supplementary material (ESM).

\section{Inclusion criteria}

Mechanical ventilation for longer than $48 \mathrm{~h}$, presence of at least one risk factor known to be associated with CIPM, and clinical suspicion of CIPM indicated by a score less than 48 in the Medical Research Council (MRC) scale assessed in 12 muscle groups [28].

\section{NAVA methods}

NAVA was used as previously described $[11,16,22,24$, $25,29]$. Briefly, the $\mathrm{EA}_{\mathrm{di}}$ was derived via a modified nasogastric feeding tube (Maquet, Solna, Sweden), processed $[11,15,30-32]$, multiplied by an adjustable proportionality constant (NAVA level), and used to control $P_{\mathrm{aw}}$ delivered by the ventilator $\left(\operatorname{Servo}^{\mathrm{i}} 3.02 .01\right.$, Maquet, Solna, Sweden).

\section{Study protocol}

Patients were studied in supine position with their head elevated by $30^{\circ}$. Sedation targets according to the Richmond agitation sedation scale (RASS) [33] were prescribed by the clinical team. A schematic study protocol is provided in Fig. E1 (ESM).

\section{Electrophysiological studies}

Peripheral nerve conduction and direct muscle stimulation studies were performed before initiation and after completion of the NAVA trial using procedures previously described [34]. The phrenic nerve was stimulated supramaximally with surface electrodes at the posterior edge of the sternocleidomastoid muscle in expiration [35]. CMAPs of the diaphragm were recorded using the electrodes of the nasogastric feeding tube. The most proximally located electrode served as the reference. The electrode depicting the largest CMAP was chosen as the active electrode. Latencies and amplitudes of the maximal CMAP were analyzed off-line. Normal values using the same equipment and technique were established in 14 healthy volunteers.

\section{Baseline measurements and implementation of NAVA}

Baseline measurements were performed using the ventilator settings prescribed by the clinical team. NAVA was used for a maximum of $72 \mathrm{~h}$. Steps 1-3 were performed daily.

\section{Step 1: NAVA level titration}

A NAVA level titration was performed as previously described [22-24]. Briefly, the NAVA level was reduced 
to a minimum of $0 \mathrm{cmH}_{2} \mathrm{O} / \mu \mathrm{V}$ (NAVAzero), resulting in virtually no assist. When $\mathrm{EA}_{\mathrm{di}}$ had stabilized at a maximum, the NAVA level was increased every $20 \mathrm{~s}$ in steps of $0.1 \mathrm{cmH}_{2} \mathrm{O} / \mu \mathrm{V}$. During the entire titration, the trend graphs for $P_{\text {aw }}$ and $V_{\mathrm{t}}$ displayed on the ventilator screen were observed. Using the same procedure, we previously described a characteristic two-phased response, i.e., a transition from an initial steep increase in $P_{\mathrm{aw}}$ and $V_{\mathrm{t}}(1 \mathrm{st}$ response) to a less steep increase in $P_{\text {aw }}$ and $V_{\mathrm{t}}$ (2nd response) [22-24]. On the basis of the interpretation that the patients' response pattern would reflect a transition from an insufficient assist level (1st response) to an assist level that meets the subject's respiratory demand (2nd response) [23], a NAVA level early after the transition from the first to the second response was identified by visual inspection of the $P_{\text {aw }}$ and $V_{\mathrm{t}}$ trend graphs and was termed adequate assist level (NAVAal).

\section{Step 2: standardized test of neuro-ventilatory efficiency} (NVET)

Neuro-ventilatory efficiency refers to the relation between the patient's neural inspiratory effort and the resulting tidal volume $\left(V_{\mathrm{t}} / \mathrm{EA}_{\mathrm{di}}\right)$. Standardized NVETs were performed daily while withholding administration of sedative drugs as part of routine care. Throughout all NVETs an inspiratory assist of $7 \mathrm{cmH}_{2} \mathrm{O}$ (or $3 \mathrm{cmH}_{2} \mathrm{O}$ if tracheotomized) was applied. Each NVET lasted for a maximum of $60 \mathrm{~min}$ or was terminated earlier when discontinuation criteria as suggested by MacIntyre et al. were fulfilled [36].

\section{Step 3: implementation of NAVAal}

NAVAal as identified in step 1 was implemented until retitration on the next day. Another mode of ventilation was only used if administration of neuromuscular blocking agents was required or if signs of respiratory failure were detected. Standard procedures, nursing, and physiotherapy were not restricted during the study.

\section{Measurements}

$P_{\mathrm{aw}}$, airflow, and $\mathrm{EA}_{\mathrm{di}}$ were recorded continuously during all NAVA level titrations and during all NVETs, and every $6 \mathrm{~h}$ during application of NAVAal. Arterial blood gases were measured twice a day. The amount of sedatives administered was recorded for $48 \mathrm{~h}$ prior to and during NAVA.

Data analysis and calculated variables

Breath-by-breath analysis was performed off-line using custom-made software (Neurovent Research Inc., Toronto,
Canada) as previously described [24]. For interindividual comparison, $\mathrm{EA}_{\mathrm{di}}$ is expressed for each patient as a percentage of the maximum inspiratory $\mathrm{EA}_{\mathrm{di}}$ at the lowest NAVA level during the titration (\%NAVAzero).

\section{Statistical analysis}

Statistical analysis was performed with SigmaStat ${ }^{\mathrm{TM}}$ (version 3.11, Systat Software Inc., San Jose, CA). Data are presented as mean $\pm \mathrm{SD}$ or median (range) as indicated by assessment of normal distribution (KolmogorovSmirnov test). Repeated measurements were analyzed using one- or two-way analysis of variance (ANOVA) or ANOVA on ranks. For two-way ANOVA a betweengroup factor was chosen as indicated and time was the repeated-measures factor. Tukey's method was used for post-test, pairwise multiple-comparison procedures. Groups with paired data were compared with the $t$ test or Wilcoxon signed-rank test. A $p$ value less than 0.05 was considered significant.

\section{Results}

Fifteen patients (age 66 [44-80] years; 7 females; APACHE II 19 [10-45]) with clinically suspected CIPM (Table 1) and 14 healthy volunteers who reported no neuromuscular disease were studied. Patients stayed in the intensive care unit for 29 (10-188) days, and were ventilated for 6 (2-25) days prior to enrolment and for 25 (7-185) days in total.

NAVAal was identified and successfully implemented in 13 patients. In patient no. 10 NAVA was terminated after $6.5 \mathrm{~h}$ because of high respiratory drive that could not be sufficiently suppressed by increasing the NAVA level, resulting in excessively high $P_{\text {aw }}$ and progressive respiratory distress. In patient no. 15 NAVA was terminated after $16 \mathrm{~h}$ because of diaphragm myocloni that repeatedly triggered the ventilator's backup mode. These two patients are not included in the analysis of repeated measurements. One patient was transferred to another hospital after $37 \mathrm{~h}$ on NAVAal and was lost to follow-up (data included in the analysis).

\section{Electrophysiological studies}

At both examinations, motor nerve studies from the median and peroneal nerves showed CMAP amplitudes lower than normal, whereas nerve conduction velocities were within normal limits. Sensory nerve action potentials from the median and sural nerves were severely abnormal or even absent in all patients. Screening for neuromuscular transmission defects by repetitive 


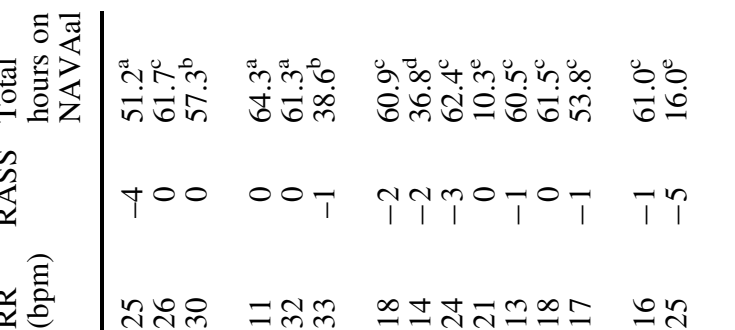

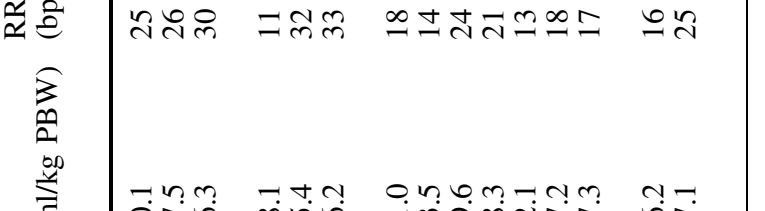

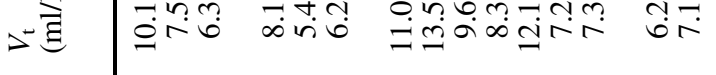

రृ:

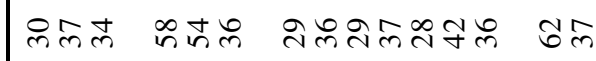

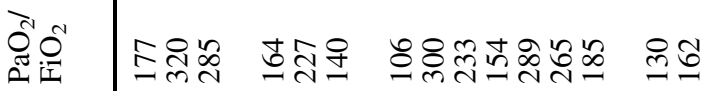

$\widehat{O}$

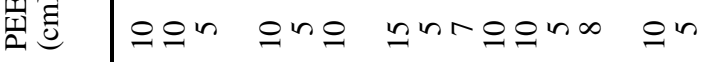

章

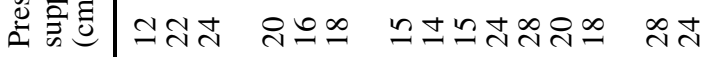

丞离

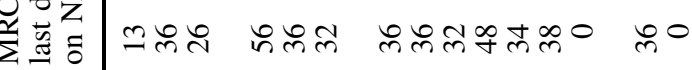

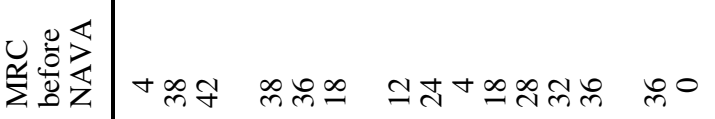

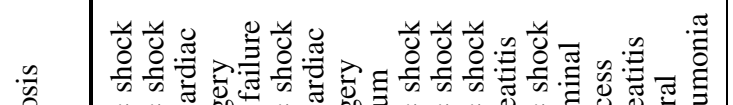

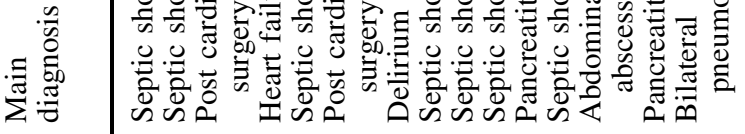

2金

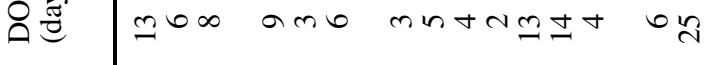

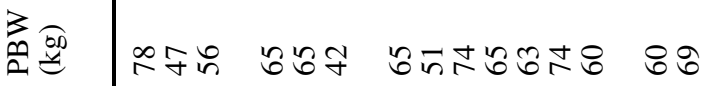

焉

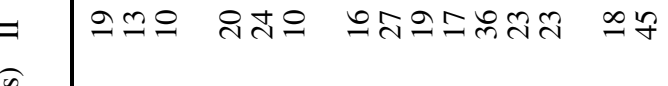

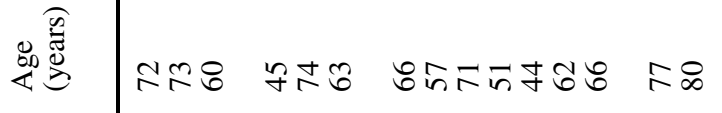

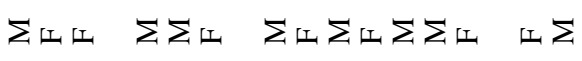

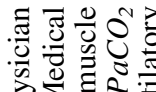

政

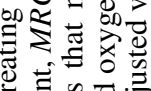

可记

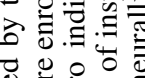

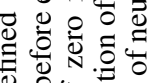

चु

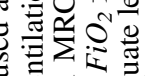

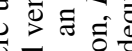

.ुँ

ใิ

돌 可

学

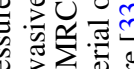

a.

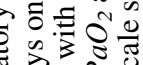

这.

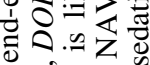

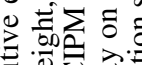

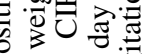

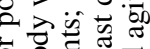

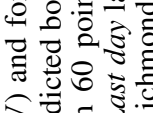

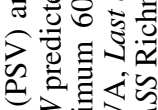

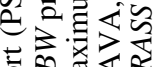

运运这

을 प

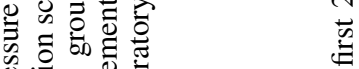

运원을

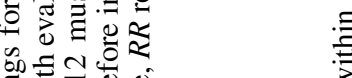

跑焉

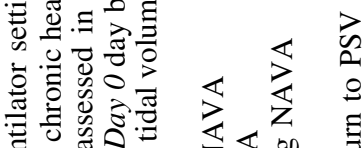

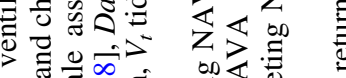

<

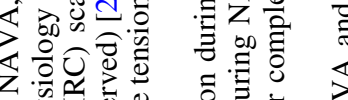

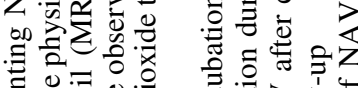

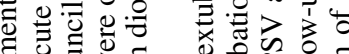

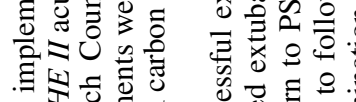

o 0

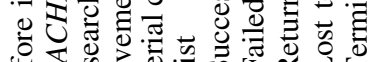




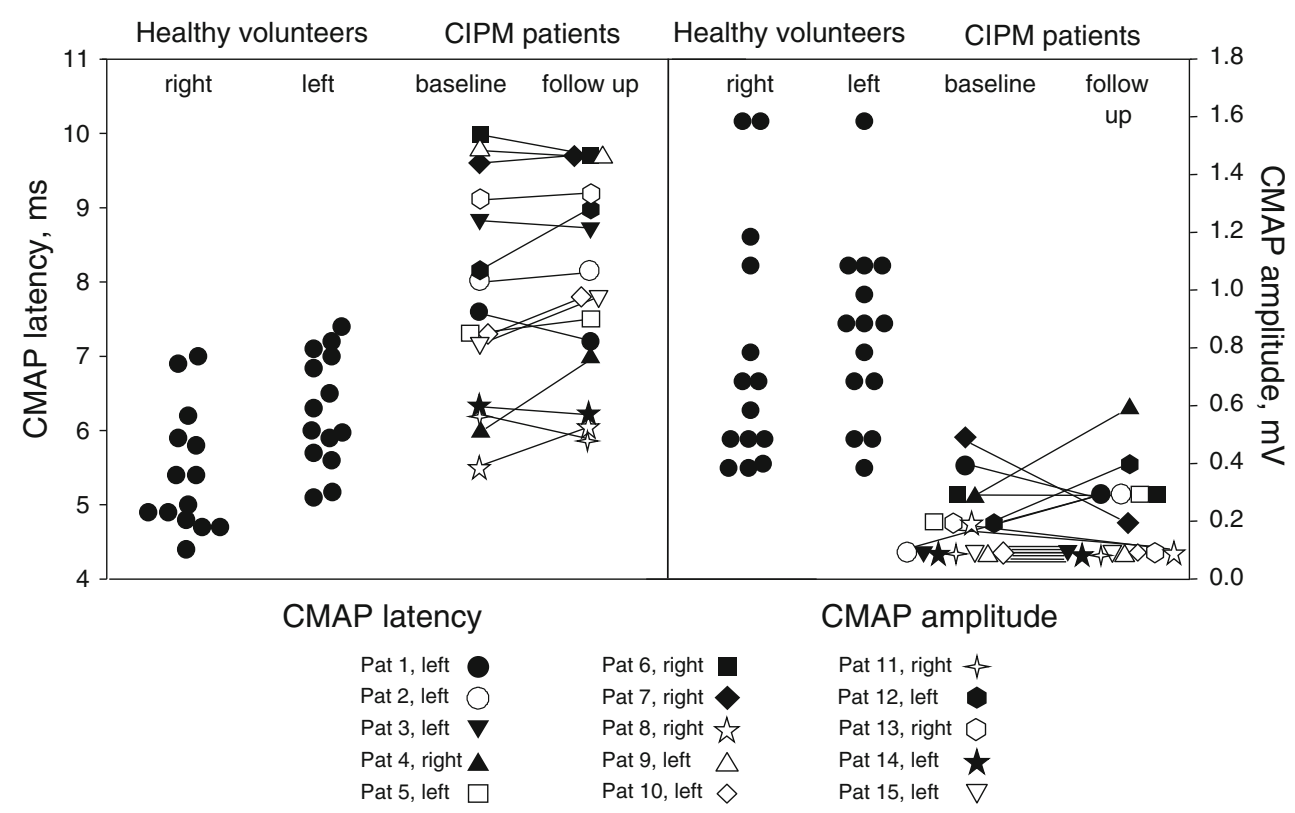

Fig. 1 Compound muscle action potentials (CMAP) of the diaphragm were recorded using the electrodes of a modified nasogastric feeding tube after transcutaneous, cervical stimulation of the phrenic nerve. Phrenic nerve latency (PNL) and CMAP amplitude were determined off-line. Each data point represents the average of three measurements. For each patient, the side of cervical stimulation is indicated in the symbol legend (left or right). Normal values were established in 14 healthy volunteers. PNL was higher and CMAP was lower in our group of 15 patients with established critical illness-associated polyneuromyopathy (CIPM) compared with healthy volunteers. There was no change over time for both parameters in CIPM patients stimulation at $3 \mathrm{~Hz}$ of the median nerve with recording from the abductor pollicis brevis muscle was normal in all patients. Electromyography of the brachioradialis and tibialis anterior muscle revealed fibrillation potentials and positive sharp waves in 3 patients at baseline and in 10 patients at follow-up. Additionally, for the brachioradialis muscle direct muscle stimulation and calculation of the ratio of the nerve and muscle evoked CMAP were performed [34]. In all patients ratios were between 0.7 and 1.0 in both examinations. The electrophysiology findings indicate that CIPM was present in all patients.

Latencies and amplitudes of diaphragm CMAP in healthy volunteers and in patients are given in Fig. 1. CMAP latency was $5.2 \mathrm{~ms}$ (4.4-7.0, right side) and $6.2 \mathrm{~ms}$ (5.1-7.4, left side) in healthy volunteers and $7.6 \mathrm{~ms}(5.5-10.0)$ in CIPM patients at baseline $(p<0.001$ vs. both sides in volunteers). CMAP amplitude was $0.9 \mathrm{mV}$ (0.4-1.6, right side) and $0.7 \mathrm{mV}(0.4-1.6$, left side) in healthy volunteers and $0.2 \mathrm{mV}(0.1-0.5)$ in CIPM patients at baseline ( $p<0.001$ vs. both sides in volunteers). Both parameters remained unchanged at follow-up in patients.

\section{Changes observed during NAVAal}

In 13 patients NAVAal was implemented for a total of 61 (37-64) h. Changes in cardio-respiratory parameters and clinical scores observed during NAVAal are given in Table 2, and Figs. 2 and E2 (ESM).

\section{NAVA level titrations}

Figure 3 depicts a typical example of a NAVA level titration. Such a titration was performed in $15,13,11$, and 10 patients at $0,24,48$, and $72 \mathrm{~h}$, respectively (Fig. E3, $\mathrm{ESM}) . V_{\mathrm{t}}$ and $\mathrm{P}_{\mathrm{aw}}$ did not change whereas $\mathrm{EA}_{\mathrm{di}}$ further decreased after reaching NAVAal despite substantial increases in the NAVA level (Table E1, ESM). In those 11 patients who had a NAVA level titration procedure at the beginning of each of the three study days, NAVAal was $1.4(1.2-2.2) \mathrm{cmH}_{2} \mathrm{O} / \mu \mathrm{V}$ at $0 \mathrm{~h}, 1.7(1.4-2.3)$ $\mathrm{cmH}_{2} \mathrm{O} / \mu \mathrm{V}$ at $24 \mathrm{~h}$, and $1.6(1.4-2.5) \mathrm{cmH}_{2} \mathrm{O} / \mu \mathrm{V}$ at $48 \mathrm{~h}$ $(p=0.332)$.

\section{Implementation of NAVAal}

From the first to the last measurement on NAVA, $\mathrm{PaO}_{2} /$ $\mathrm{FiO}_{2}$ increased $(p=0.007)$, while $V_{\mathrm{t}}, \mathrm{RR}$, mean inspiratory $\mathrm{EA}_{\mathrm{di}}$, mean inspiratory $P_{\mathrm{aw}}$ above PEEP, $V_{\mathrm{t}} / \mathrm{EA}_{\mathrm{di}}$, $\mathrm{PaCO}_{2}$, heart rate, and mean arterial pressure remained unchanged $(p>0.05$ for all) (Table 2).

The average $V_{\mathrm{t}}$ during the entire NAVA period was $6.5(3.7-14.3) \mathrm{ml} / \mathrm{kg}$ predicted body weight (PBW) and 


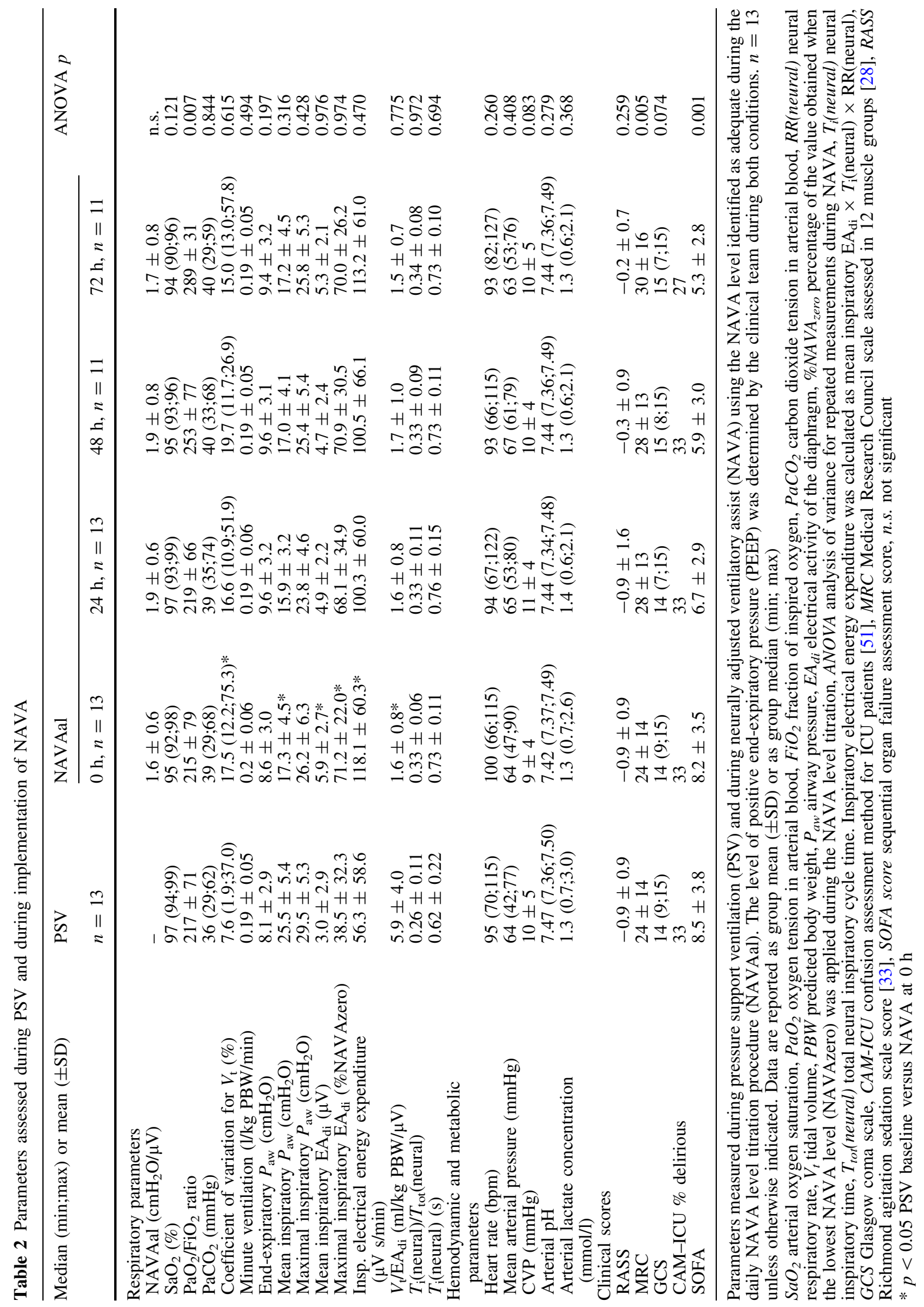


Fig. 2 Changes in tidal volume $\left(V_{\mathrm{t}}\right)$, respiratory rate, mean inspiratory airway pressure $\left(P_{\text {aw }}\right)$ on top of positive endexpiratory pressure (PEEP), and maximal inspiratory electrical activity of the diaphragm $\left(\mathrm{EA}_{\mathrm{di}}\right)$ when implementing NAVA for 72 h. $V_{\mathrm{t}}$ and mean inspiratory $P_{\text {aw }}$ on top of PEEP decreased, while respiratory rate and $\mathrm{EA}_{\mathrm{di}}$ increased when switching from PSV to NAVA. All parameters remained unchanged when

NAVA was implemented for a maximum of three consecutive days
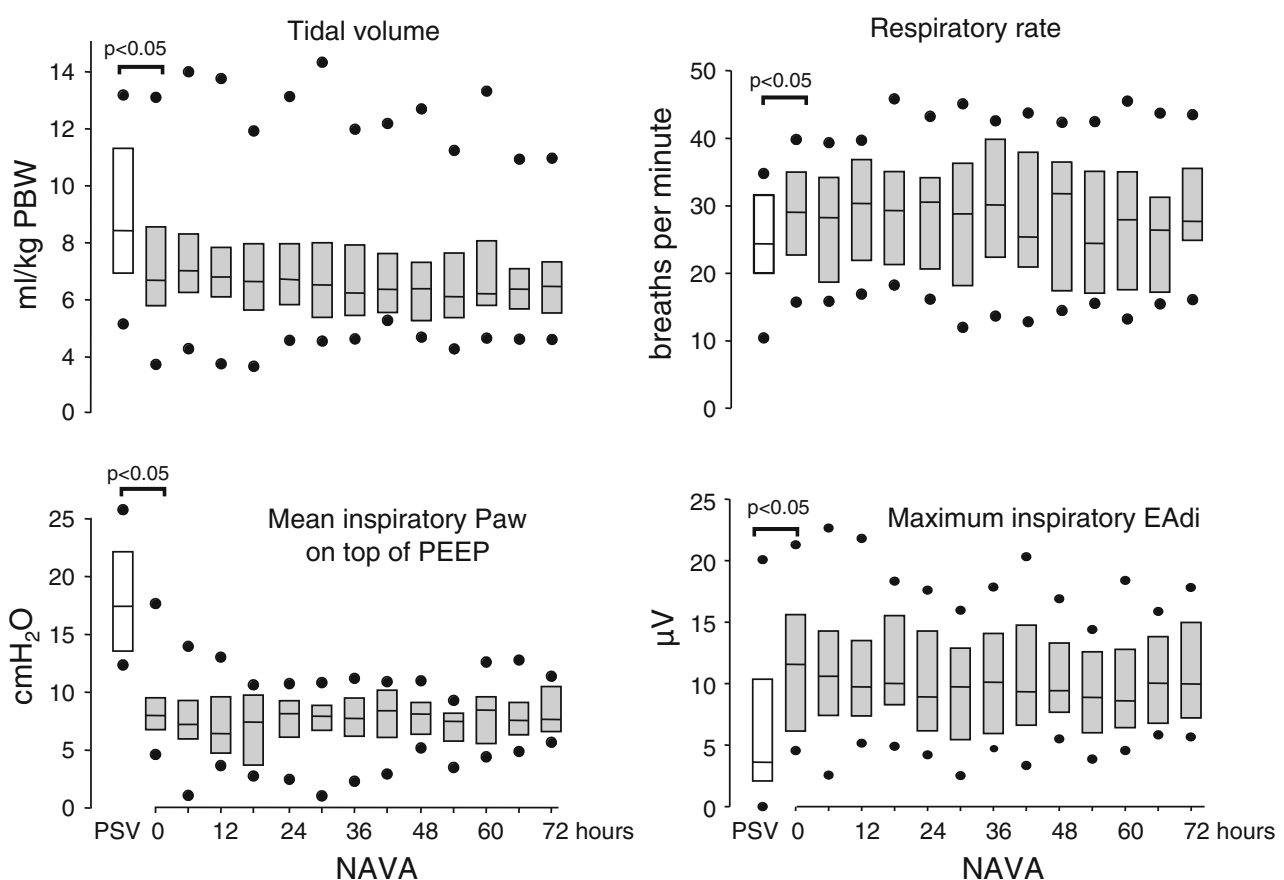

median $\left(25^{\text {th }}-75^{\text {th }}\right.$ quartiles $)$

- minimum and maximum of the group

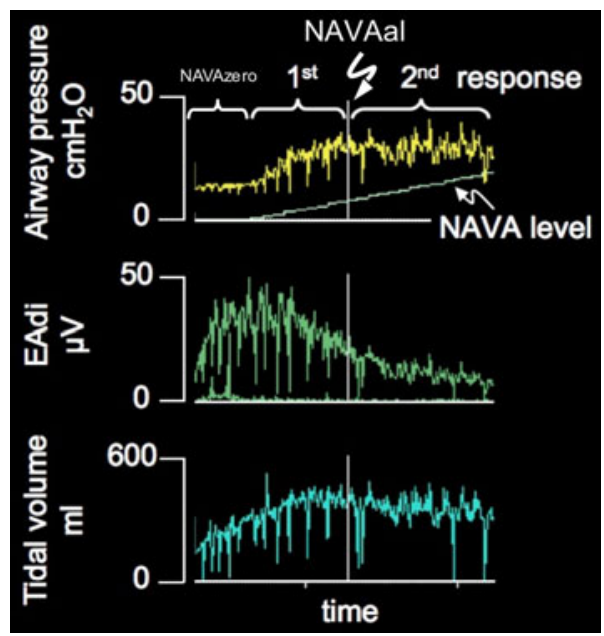

Fig. 3 NAVA level titration in patient no. 11 at baseline. The method used to identify an adequate NAVA level (NAVAal) during systematic increases in the NAVA level has been described previously [22-24]. Briefly, the NAVA level was first reduced to a minimal level of $0 \mathrm{cmH}_{2} \mathrm{O} / \mu \mathrm{V}$ (NAVAzero), resulting in virtually no assist and in an increase in the $\mathrm{EA}_{\mathrm{di}}$. When $\mathrm{EA}_{\mathrm{di}}$ had stabilized at a maximum, the NAVA level was increased every $20 \mathrm{~s}$ in steps of $0.1 \mathrm{cmH}_{2} \mathrm{O} / \mu \mathrm{V}$. A NAVA level early after the transition from an initial steep increase in $P_{\text {aw }}$ and $V_{\mathrm{t}}$ (1st response) to a less steep increase in $P_{\text {aw }}$ and $V_{\mathrm{t}}$ (2nd response) was identified by visual inspection of $P_{\text {aw }}$ and $V_{\mathrm{t}}$ trend graphs displayed on the ventilator screen, and was termed adequate assist level (NAVAal)

was positively correlated with both CMAP latency $\left(r^{2}=\right.$ $0.305 ; p=0.033)$ and CMAP amplitude $\left(r^{2}=0.715\right.$; $p=0.002$ ) at baseline (Fig. 4). The electrical energy expenditure, a parameter reflecting the respiratory drive spent to generate minute ventilation, did not change during implementing NAVAal. PEEP was 9.7 (4.814.7) $\mathrm{cmH}_{2} \mathrm{O}$ when starting NAVAal and remained unchanged at $9.0(5.7-16.0) \mathrm{cmH}_{2} \mathrm{O}$ during the last measurements on NAVAal $(p=0.25)$.

During NAVA the MRC score increased, while the SOFA score decreased, and RASS, GCS, and CAM-ICU remained unchanged (Table 2).

In those patients that received fentanyl, propofol, or midazolam during the $48 \mathrm{~h}$ preceding and/or during NAVA the amounts were less during NAVA for fentanyl ( $n=13 ; 163[0-437] \mu \mathrm{g} /$ patient per day before NAVA and $92[0-229] \mu \mathrm{g} /$ patient per day during NAVA) and for midazolam $(n=7 ; 5[0-15] \mathrm{mg} /$ patient per day before NAVA and 0 [0-4] mg/patient per day during NAVA), and were equal for propofol $(n=13,125[0-8,640] \mathrm{mg} /$ patient per day before NAVA and $133[0-4,800] \mathrm{mg} /$ patient per day during NAVA).

Neuro-ventilatory efficiency tests

NVETs were performed daily in all patients. $V_{\mathrm{t}} / \mathrm{EA}_{\mathrm{di}}$ decreased during the first NVET, from $1.1 \pm 0.6$ to $0.9 \pm 0.4 \mathrm{ml} / \mathrm{kg} \mathrm{PBW} / \mu \mathrm{V}$, while it increased from $0.9 \pm 0.6$ to $1.0 \pm 0.8 \mathrm{ml} / \mathrm{kg} \mathrm{PBW} / \mu \mathrm{V}$ during the last NVET performed $(p=0.048$; ANOVA time-group interaction) (Table 3). Changes in $V_{\mathrm{t}}, \mathrm{RR}$, and $P_{\mathrm{aw}}$ above PEEP were not different between the first and last NVET. 
Fig. 4 Relationship between individual average tidal volume $\left(V_{\mathrm{t}}\right)$ during NAVA and the phrenic nerve compound muscle action potential (CMAP) latency (PNL) and amplitude. The average $V_{\mathrm{t}}$ during NAVA ranged from roughly 4 to $9 \mathrm{ml} / \mathrm{kg}$ PBW (except in one patient), and was correlated to both PNL and CMAP amplitude. This may indicate that feedback control of $V_{\mathrm{t}}$ during NAVA is, to a limited extent, influenced by the degree of phrenic neuropathy
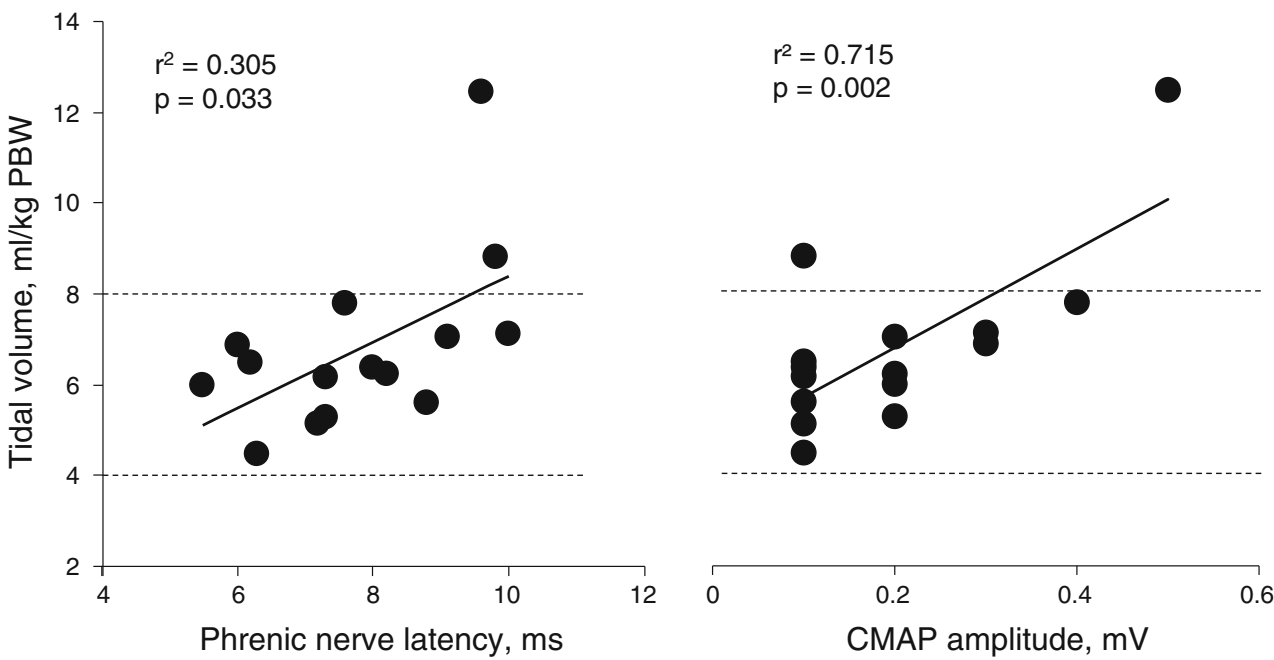

Table 3 Changes in neuro-ventilatory parameters during standardized tests of neuro-ventilatory efficiency (NVET)

\begin{tabular}{lllll}
\hline$n=12$ & & Start of NVET & End of NVET & MANOVA time-group interaction \\
\hline$V_{\mathrm{t}} / \mathrm{EA}_{\mathrm{di}}(\mathrm{ml} / \mathrm{kg} \mathrm{PBW} / \mu \mathrm{V})$ & First NVET & $1.1 \pm 0.6$ & $0.9 \pm 0.4$ & $p=0.048$ \\
Tidal volume $(\mathrm{ml} / \mathrm{kg} \mathrm{PBW})$ & Last NVET & $0.9 \pm 0.6$ & $1.0 \pm 0.8$ & $p=0.749$ \\
& First NVET & $6.2 \pm 2.6$ & $6.6 \pm 2.4$ & \\
Respiratory rate (breaths/min) & Last NVET & $5.6 \pm 1.3$ & $6.0 \pm 1.5$ & $p=0.345$ \\
\multirow{2}{*}{ Mean insp. $P_{\mathrm{aw}}$ above PEEP $\left(\mathrm{cmH}_{2} \mathrm{O}\right)$} & First NVET & $33 \pm 18$ & $30 \pm 11$ & \\
& Last NVET & $30 \pm 10$ & $31 \pm 10$ & $p=0.244$ \\
& First NVET & $4.8 \pm 1.8$ & $4.7 \pm 1.9$ & \\
\hline
\end{tabular}

Changes observed during the first and the last available standardized tests of neuro-ventilatory efficiency (NVET) on pressure support ventilation (PSV). Throughout the NVETs an inspiratory assist of $7 \mathrm{cmH}_{2} \mathrm{O}$ (or $3 \mathrm{cmH}_{2} \mathrm{O}$ if tracheotomized) was applied

The proportion of unsuccessful NVETs was $4 / 15$ at $0 \mathrm{~h}, 5 / 13$ at $24 \mathrm{~h}, 3 / 10$ at $48 \mathrm{~h}$, and $1 / 8$ at $72 \mathrm{~h}$. Seven patients were not extubated despite successful NVETs due to an impaired level of consciousness (GCS $<9$; $n=3)$ or due to a high level of PEEP $(n=4)$. Five patients were liberated from mechanical ventilation during the study, two of whom required re-intubation within $48 \mathrm{~h}$ due to progressive respiratory failure.

\section{Discussion}

The present study demonstrates for the first time that central respiratory response is adequate such that NAVA can be safely applied for up to 3 days in critically ill patients with established CIPM including phrenic nerve neuropathy.

CIPM was present in all our patients as evidenced by reduced MRC scores and the electrophysiology studies. Our results for both PNL and CMAP in healthy subjects and critically ill patients are comparable to those of
$V_{t}$ tidal volume, $P B W$ predicted body weight, $P_{a w}$ airway pressure, $E A_{d i}$ electrical activity of the diaphragm, PEEP positive endexpiratory pressure, MANOVA multivariate analysis of variance

previous studies [6-10, 35, 37-40]. Although group mean values in our patients were higher for PNL and lower for CMAP compared with healthy volunteers, the data overlapped between the groups, supporting previous findings that the phrenic nerve-diaphragm unit might be affected to a variable degree in patients with CIPM [41, 42].

Vagally mediated, lung-protective reflexes play a major role in modulating respiratory drive [43-46]. Despite impaired neural function in our patients, the $\mathrm{EA}_{\mathrm{di}}$ was progressively downregulated via neural feedback control when the NAVA level was increased, resulting in a characteristic two-phase response in $V_{\mathrm{t}}$ and $P_{\text {aw }}$ that allows for identification of NAVAal, as previously described in animals and humans [22-25]. At NAVAal, the $\mathrm{EA}_{\mathrm{di}}$ amplitude averaged about $10 \mu \mathrm{V}$ and was reduced to approximately $70 \%$ of the values observed when only minimal assist was applied (i.e., at NAVAzero).

The positive correlation between $V_{\mathrm{t}}$ and parameters of phrenic nerve function, i.e., PNL and CMAP amplitude, may provide indirect evidence that the neural feedback system is progressively impaired in relation to the degree 
of severity of polyneuropathy. However, the fact that during NAVAal our patients chose a $V_{\mathrm{t}}$ within boundaries that are conventionally regarded as lung protective (i.e., 4-9 $\mathrm{ml} / \mathrm{kg}$ PBW, except for one patient), displayed high $V_{\mathrm{t}}$ variability, kept their $\mathrm{RR}$ (neural) stable, controlled $\mathrm{PaCO}_{2}$ levels, improved oxygenation, and maintained the $\mathrm{EA}_{\mathrm{di}}$ at the titrated level, indicates that vagally mediated feedback to the respiratory centers was sufficiently preserved to use NAVA.

The physiological response during the titration procedures that was similar to what we found in a general population of critically ill patients [22] and the stability during prolonged implementation of NAVAal without evidence of progression to respiratory failure, indicate that NAVA can be safely applied in patients with CIPM. Indeed, individual titration of the assist to a level that maintains muscular function at a comfortable level at all times without inducing fatigue may portend the potential to condition respiratory muscles and hence prevent or attenuate ventilator-induced respiratory muscle dysfunction.

Similar to our previous work [22-25], increasing the NAVA level above NAVAal reduced, but did not abolish, $\mathrm{EA}_{\mathrm{di}}$, while the $V_{\mathrm{t}}$ (and hence the transpulmonary pressure) remained constant over a wide range of NAVA levels. Thus, the patient-controlled limitation of $V_{\mathrm{t}}$ with NAVA may also help in reducing the propensity for ventilator-induced lung injury, as recently shown in animals and patients with acute respiratory distress syndrome (ARDS) [20, 47].

Although the majority of our patients were given lower doses of analgesic and sedative drugs during NAVA compared with the preceding PSV period, this might be due to improvement in the patients' condition and not necessarily to the mode of mechanical ventilation. Additional work is required to determine how improved patient-ventilator interaction impacts other aspects of treatment.

NAVA was prematurely terminated in two patients because of suspected uncoupling between respiratory motor output and respiratory demand and because of diaphragm myocloni, illustrating that NAVA might not be suitable for all patients at all times. Conditions associated with excessively high $\mathrm{CO}_{2}$ production or with disturbed function of breathing centers may result in overexertion of the sensomotor feedback system that controls $\mathrm{EA}_{\mathrm{di}}$, and may temporarily require an alternative approach [48] or more controlled modes of ventilation until resolution.

\section{Standardized neuro-ventilatory efficiency tests}

The ratio between $V_{\mathrm{t}}$ and $\mathrm{EA}_{\mathrm{di}}$ during NAVA reflects the conversion of respiratory drive into tidal ventilation [24]. In the present study, $V_{\mathrm{t}} / \mathrm{EA}_{\mathrm{di}}$ decreased during the first NVET, whereas it slightly increased during the last NVET.
The clinical relevance of the neuro-ventilatory efficiency index is that an increase of the index over time indicates that a patient is able to generate more $V_{\mathrm{t}}$ for a given respiratory drive whereas a decrease in the index over time suggests the opposite. Both components of the index are easily available: $V_{\mathrm{t}}$ is calculated by all mechanical ventilators and the $\mathrm{EA}_{\mathrm{di}}$ can be reliably acquired using a modified nasogastric feeding tube [22, 49]. In contrast, continuous monitoring of the various components of respiratory system mechanics and respiratory muscle load is not straightforward. Clearly, our index simply indicates that a patient improved or worsened the efficiency in converting electrical neuromuscular activity into tidal ventilation, but does not discriminate between contributing factors such as changes in respiratory muscle force or load, in respiratory system mechanics, in chest wall configuration, in intrinsic PEEP, and in gas tension. Thus, without additional information, changes of the index alone do not allow one to draw conclusions about which combination of factors has been affected and caused the change.

Since a constant level of assist was delivered during all NVETs, our results reflect either an improvement of the respiratory neuromuscular function or a decrease in the respiratory load over time. We did not assess respiratory system mechanics, but a relevant change in the respiratory load during the NVET seems unlikely. Although the changes of $V_{\mathrm{t}} / \mathrm{EA}_{\mathrm{di}}$ over time during the first and last NVET differed statistically significantly, the magnitude of the changes was small. Further work is required to confirm our results and to evaluate NVET as a weaning predictor.

\section{Limitations}

We did not assess inspiratory pressure generation in our patients and are hence unable to determine the extent of respiratory muscle weakness and its eventual association with increased PNL and reduced CMAP amplitude. Luo et al. [39] found a positive correlation between twitch $P_{\mathrm{di}}$ and CMAP amplitude (but no relationship between twitch $P_{\mathrm{di}}$ and PNL). In another study, CMAP has been suggested to reflect the number of diaphragmatic muscle fibers that can be activated by phrenic nerve stimulation [50].

\section{Conclusions}

Our results suggest that the respiratory center's output is accurate and vagally mediated reflexes are sufficient in most critically ill patients with established CIPM, such that implementation of NAVA for up to 3 days results in stable cardiopulmonary function while preserving respiratory drive. Our study confirms that NAVA efficiently limits the risk of excessive assist delivery and patient- 
ventilator asynchrony, both frequently observed during pneumatically controlled modes such as PSV. Whether assessment of neuro-ventilatory efficiency helps inform the weaning process requires further evaluation.

Acknowledgments We are indebted to the study patients for their participation, to Jeannie Wurz for editing the manuscript and to Norman Comtois for his assistance with analyzing the data. We thank the physicians and the nursing staff of the Department of Intensive Care Medicine, Bern University Hospital, Inselspital, Bern, for their invaluable support and cooperation. This study was supported by a grant from the Swiss National Science Foundation (SNF) 3200B0-113478/1 and from the Stiftung für die Forschung in Anästhesiologie und Intensivmedizin, Bern (18/2006), awarded to Lukas Brander. Christer Sinderby is supported by the McLaughlin Foundation.
Conflict of interest The Department of Intensive Care Medicine at the Bern University Hospital has a research and development collaboration contract with Maquet Critical Care AB. None of the authors from this department received any personal financial gain from this collaboration. Dr. Sinderby has patented inventions related to neural control of mechanical ventilation. The license for these patents belongs to Maquet Critical Care. Commercial use of this technology provides financial benefit to Dr. Sinderby through royalties. Dr. Sinderby owns $50 \%$ of Neurovent Research Inc. Neurovent Research is a research and development company that builds the equipment and catheters for research studies. Neurovent Research has a consulting agreement with Maquet Critical Care. Dr. Brander was an invited speaker at symposiums sponsored by Maquet Critical Care $\mathrm{AB}$ but did not receive any personal financial gain.

\section{References}

1. Ali NA, O’Brien JM Jr, Hoffmann SP, Phillips G, Garland A, Finley JC, Almoosa K, Hejal R, Wolf KM, Lemeshow S, Connors AF Jr, Marsh CB (2008) Acquired weakness, handgrip strength, and mortality in critically ill patients. Am J Respir Crit Care Med 178:261-268

2. De JB, Sharshar T, Lefaucheur JP, Authier FJ, Durand-Zaleski I, Boussarsar M, Cerf C, Renaud E, Mesrati F, Carlet J, Raphael JC, Outin H, Bastuji-Garin S (2002) Paresis acquired in the intensive care unit: a prospective multicenter study. JAMA 288:2859-2867

3. De JB, Bastuji-Garin S, Sharshar T, Outin H, Brochard L (2004) Does ICUacquired paresis lengthen weaning from mechanical ventilation? Intensive Care Med 30:1117-1121

4. Garnacho-Montero J, Madrazo-Osuna J, Garcia-Garmendia JL, Ortiz-Leyba C, Jimenez-Jimenez FJ, BarreroAlmodovar A, Garnacho-Montero MC, Moyano-Del-Estad MR (2001) Critical illness polyneuropathy: risk factors and clinical consequences. A cohort study in septic patients. Intensive Care Med 27:1288-1296

5. Sharshar T, Bastuji-Garin S, Stevens RD, Durand MC, Malissin I, Rodriguez P, Cerf C, Outin H, De JB (2009) Presence and severity of intensive care unit-acquired paresis at time of awakening are associated with increased intensive care unit and hospital mortality. Crit Care Med 37:3047-3053

6. Zochodne DW, Bolton CF, Wells GA, Gilbert JJ, Hahn AF, Brown JD, Sibbald WA (1987) Critical illness polyneuropathy. A complication of sepsis and multiple organ failure. Brain 110 (Pt 4):819-841
7. Maher J, Rutledge F, Remtulla H, Parkes A, Bernardi L, Bolton CF (1995) Neuromuscular disorders associated with failure to wean from the ventilator. Intensive Care Med 21:737-743

8. Spitzer AR, Giancarlo T, Maher L, Awerbuch G, Bowles A (1992) Neuromuscular causes of prolonged ventilator dependency. Muscle Nerve 15:682-686

9. Witt NJ, Zochodne DW, Bolton CF, Grand'Maison F, Wells G, Young GB, Sibbald WJ (1991) Peripheral nerve function in sepsis and multiple organ failure. Chest 99:176-184

10. Zifko UA, Zipko HT, Bolton CF (1998) Clinical and electrophysiological findings in critical illness polyneuropathy. J Neurol Sci 159:186-193

11. Sinderby C, Navalesi P, Beck J, Skrobik Y, Comtois N, Friberg S, Gottfried SB, Lindstrom L (1999) Neural control of mechanical ventilation in respiratory failure. Nat Med 5:1433-1436

12. ATS/ERS (2002) ATS/ERS Statement on respiratory muscle testing. Am $\mathbf{J}$ Respir Crit Care Med 166:518-624

13. Beck J, Sinderby C, Lindstrom L, Grassino A (1998) Effects of lung volume on diaphragm EMG signal strength during voluntary contractions. J Appl Physiol 85:1123-1134

14. Jolley CJ, Luo YM, Steier J, Reilly C, Seymour J, Lunt A, Ward K, Rafferty GF, Polkey MI, Moxham J (2009) Neural respiratory drive in healthy subjects and in COPD. Eur Respir J 33:289-297

15. Sinderby C, Beck J, Spahija J, Weinberg J, Grassino A (1998) Voluntary activation of the human diaphragm in health and disease. J Appl Physiol 85:2146-2158
16. Beck J, Campoccia F, Allo JC, Brander L, Brunet F, Slutsky AS, Sinderby C (2007) Improved synchrony and respiratory unloading by neurally adjusted ventilatory assist (NAVA) in lung-injured rabbits. Pediatr Res 61:289-294

17. Colombo D, Cammarota G, Bergamaschi V, De LM, Corte FD, Navalesi P (2008) Physiologic response to varying levels of pressure support and neurally adjusted ventilatory assist in patients with acute respiratory failure. Intensive Care Med 34:2010-2018

18. Piquilloud L, Vignaux L, Bialais E, Roeseler J, Sottiaux T, Laterre PF, Jolliet P, Tassaux D (2010) Neurally adjusted ventilatory assist improves patient-ventilator interaction. Intensive Care Med 37:263-271

19. Spahija J, de Marchie M, Albert M, Bellemare P, Delisle S, Beck J, Sinderby C (2010) Patient-ventilator interaction during pressure support ventilation and neurally adjusted ventilatory assist. Crit Care Med 38:518-526

20. Terzi N, Pelieu I, Guittet L, Ramakers M, Seguin A, Daubin C, Charbonneau P, du Cheyron D, Lofaso F (2010) Neurally adjusted ventilatory assist in patients recovering spontaneous breathing after acute respiratory distress syndrome: physiological evaluation. Crit Care Med 38:1830-1837

21. Allo JC, Beck JC, Brander L, Brunet F, Slutsky AS, Sinderby CA (2006) Influence of neurally adjusted ventilatory assist and positive endexpiratory pressure on breathing pattern in rabbits with acute lung injury. Crit Care Med 34:2997-3004 
22. Brander L, Leong-Poi H, Beck J, Brunet F, Hutchison SJ, Slutsky AS, Sinderby C (2009) Titration and implementation of neurally adjusted ventilatory assist in critically ill patients. Chest 135:695-703

23. Lecomte F, Brander L, Jalde F, Beck J, Qui H, Elie C, Slutsky AS, Brunet F, Sinderby C (2009) Physiological response to increasing levels of neurally adjusted ventilatory assist (NAVA). Respir Physiol Neurobiol 166:117-124

24. Passath C, Takala J, Tuchscherer D, Jakob SM, Sinderby C, Brander L (2010) Physiologic response to changing positive end-expiratory pressure during neurally adjusted ventilatory assist in sedated, critically ill adults. Chest 138:578-587

25. Sinderby C, Beck J, Spahija J, de Marchie M, Lacroix J, Navalesi P, Slutsky AS (2007) Inspiratory muscle unloading by neurally adjusted ventilatory assist during maximal inspiratory efforts in healthy subjects. Chest 131:711-717

26. Roze H, Lafrikh A, Perrier V, Germain A, Dewitte A, Gomez F, Janvier G, Ouattara A (2011) Daily titration of neurally adjusted ventilatory assist using the diaphragm electrical activity. Intensive Care Med 37:1087-1094

27. Ververidis D, Van GM, Passath C, Takala J, Brander L (2011) Identification of adequate neurally adjusted ventilatory assist (NAVA) during systematic increases in the NAVA level. IEEE Trans Biomed Eng, Jun 16 (e-pub ahead of print), PMID: 21690003

28. Kleyweg RP, van der Meche FG, Schmitz PI (1991) Interobserver agreement in the assessment of muscle strength and functional abilities in Guillain-Barre syndrome. Muscle Nerve 14:1103-1109

29. Beck J, Reilly M, Grasselli G, Mirabella L, Slutsky AS, Dunn MS, Sinderby C (2009) Patient-ventilator interaction during neurally adjusted ventilatory assist in low birth weight infants. Pediatr Res 65:663-668

30. Sinderby CA, Beck JC, Lindstrom LH, Grassino AE (1997) Enhancement of signal quality in esophageal recordings of diaphragm EMG. J Appl Physiol 82:1370-1377

31. Sinderby C, Spahija J, Beck J (2001) Changes in respiratory effort sensation over time are linked to the frequency content of diaphragm electrical activity. Am J Respir Crit Care Med 163:905-910
32. Sinderby C, Spahija J, Beck J, Kaminski D, Yan S, Comtois N, Sliwinski P (2001) Diaphragm activation during exercise in chronic obstructive pulmonary disease. Am J Respir Crit Care Med 163:1637-1641

33. Sessler CN, Gosnell MS, Grap MJ, Brophy GM, O'Neal PV, Keane KA, Tesoro EP, Elswick RK (2002) The Richmond agitation-sedation scale: validity and reliability in adult intensive care unit patients. Am J Respir Crit Care Med 166:1338-1344

34. Z'graggen WJ, Brander L, Tuchscherer D, Scheidegger O, Takala J, Bostock $\mathrm{H}$ (2011) Muscle membrane dysfunction in critical illness myopathy assessed by velocity recovery cycles. Clin Neurophysiol 122:834-841

35. Swenson MR, Rubenstein RS (1992) Phrenic nerve conduction studies. Muscle Nerve 15:597-603

36. MacIntyre NR, Cook DJ, Ely EW Jr, Epstein SK, Fink JB, Heffner JE, Hess D, Hubmayer RD, Scheinhorn DJ (2001) Evidence-based guidelines for weaning and discontinuing ventilatory support: a collective task force facilitated by the American College of Chest Physicians; the American Association for Respiratory Care; and the American College of Critical Care Medicine. Chest 120:375S-395S

37. Mier A, Brophy C, Moxham J, Green M (1987) Phrenic nerve stimulation in normal subjects and in patients with diaphragmatic weakness. Thorax 42:885-888

38. Luo YM, Polkey MI, Johnson LC, Lyall RA, Harris ML, Green M, Moxham J (1998) Diaphragm EMG measured by cervical magnetic and electrical phrenic nerve stimulation. J Appl Physiol 85:2089-2099

39. Luo YM, Lyall RA, Lou HM, Rafferty GF, Polkey MI, Moxham J (1999) Quantification of the esophageal diaphragm electromyogram with magnetic phrenic nerve stimulation. Am J Respir Crit Care Med 160:1629-1634

40. Beck J, Weinberg J, Hamnegard CH, Spahija J, Olofson J, Grimby G, Sinderby C (2006) Diaphragmatic function in advanced Duchenne muscular dystrophy. Neuromuscul Disord 16:161-167

41. McKeown MJ, Bolton CF (1998) Electromyography of the diaphragm in neuromuscular disease. Muscle Nerve 21:954-957
42. Wanke T, Paternostro-Sluga T, Grisold W, Formanek D, Auinger M, Zwick H, Irsigler K (1992) Phrenic nerve function in type 1 diabetic patients with diaphragm weakness and peripheral neuropathy. Respiration 59:233-237

43. Hering E, Breuer J (1868) Die Selbststeurung der athmung durch den nervus vagus. Sitzber Deut Akad Wiss Wein 57:672-677

44. Rabbette PS, Costeloe KL, Stocks J (1991) Persistence of the Hering-Breuer reflex beyond the neonatal period. J Appl Physiol 71:474-480

45. Stanley NN, Altose MD, Kelsen SG, Ward CF, Cherniack NS (1975) Changing effect of lung volume on respiratory drive in man. J Appl Physiol 38:768-773

46. Widdicombe JG, Tatar M (1988) Upper airway reflex control. Ann N Y Acad Sci 533:252-261

47. Brander L, Sinderby C, Lecomte F, Leong-Poi H, Bell D, Beck J, Tsoporis JN, Vaschetto R, Schultz MJ, Parker TG, Villar J, Zhang H, Slutsky AS (2009) Neurally adjusted ventilatory assist decreases ventilator-induced lung injury and non-pulmonary organ dysfunction in rabbits with acute lung injury. Intensive Care Med 35:1979-1989

48. Karagiannidis C, Lubnow M, Philipp A, Riegger GA, Schmid C, Pfeifer M, Mueller T (2010) Autoregulation of ventilation with neurally adjusted ventilatory assist on extracorporeal lung support. Intensive Care Med 36:2038-2044

49. Barwing J, Ambold M, Linden N, Quintel M, Moerer O (2009) Evaluation of the catheter positioning for neurally adjusted ventilatory assist. Intensive Care Med 35:1809-1814

50. Markand ON, Kincaid JC, Pourmand RA, Moorthy SS, King RD, Mahomed Y, Brown JW (1984) Electrophysiologic evaluation of diaphragm by transcutaneous phrenic nerve stimulation. Neurology 34:604-614

51. Ely EW, Margolin R, Francis J, May L, Truman B, Dittus R, Speroff T, Gautam S, Bernard GR, Inouye SK (2001) Evaluation of delirium in critically ill patients: validation of the confusion assessment method for the intensive care unit (CAM-ICU). Crit Care Med 29:1370-1379 